as yet little that is peculiar told us regarding its cultivation, chemical, vital, anatomical and pathological relations, distant observers have to rely for guidance chiefly upon the morphological characters of the newly described cholera bacillus; and, unfortunately, I have not been able in India to see an authentic specimen of this organism. It is, therefore, the more remarkable that "E. K.," who in Europe has enjoyed such advantage, not the less arrives at results not much differing (as I judge) from those attained both previously and independently in Western India. Here, at least, is a noteworthy concordance. But in his identification, " $E \mathrm{~K}$." ventures further when asserting that " particularly a vibrio rugula" 1 is the organism which Dr. Koch describes as a

Organisms in Alvine Dejecta (Indian Cholera).

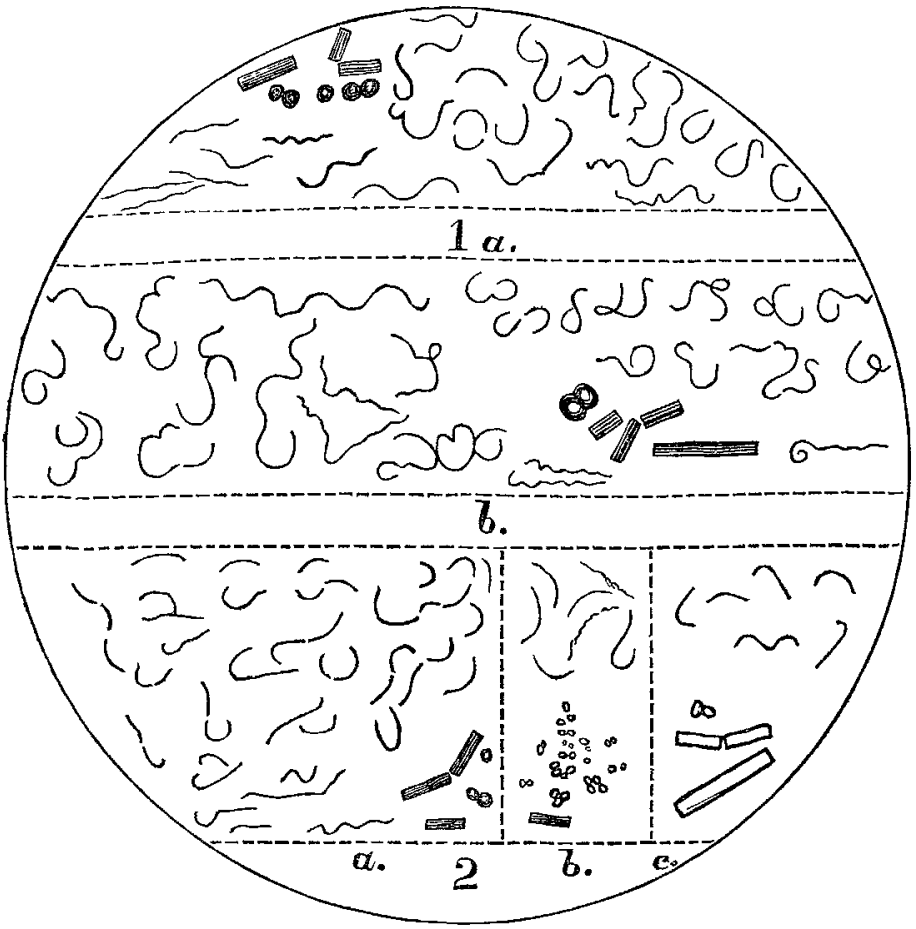

The so-called Cholera Bacillus (?), Vibrio (?), stained with roseine.

Fig. 1.-From fresh rice-water-like stools of a case which recovered; patient a low-caste man and a foul feeder probably. $a$, Common forms seen. $b$, Less frequent forms, and resembling vibriones more. A few ordınary putrefactive bacteria are shown, which will serve for purposes of comparison. $\times 800:{ }_{1}^{x}$ in., oil immersion. Fig. 2-From a case of cholera supervening on variola (late stage) which proved fatal; material also fresh. a b c, Forms seen upon successive days, after which the stools became thicker and deep-coloured. $\times 650: \frac{1}{10}$ in., water immersion.

"comma-shaped' bacillus ;" and if he be right, it well-nigh inevitably follows that the real cholera germ (if such truly exist) has still to be found. Because, first, it is a priori irrational to suppose that an everywhere widely distributed organism like vibrio rugula can alone be the essential cause of Asiatic cholera; and next, it is most improbable that mere imagination could have dominated the judgment of Dr. Koch. Doubtless the inference intended in Nature is that the so-c alled cholera bacillus is a myth; and be this as it may, some further details of the great discovery, declared to be assured, are now more than ever needed, especially by deeply interested inquirers in India.

Bombay.

\section{Sp. Cohn.}

National Assoctation for the Promotion of Socral ScIENCE.-At the meeting of this Association, which is to be held in Birmingham from the 17 th to the 24th inst., the following special questions will be discussed in the Health Department, of which Dr. Norman Chevers is president:-The best method of dealing with town sewage, the products of house and street scavenging, and the products of combustion; the best means of securing those improvements in the dwellings of the poor which are essential to the welfare of the community ; and how far the average death-rate of a population may be considered an efficient test of its sanitary condition. The hon. secretaries of this department are Mr. H. H. Collins and Dr. E. Seaton; and the hon. local secretaries, Messrs. G. A. Panton and R. M. Simon.
REMARKS ON THE

\section{TREATMENT OF SYPHILIS BY HYPODERMIC \\ INJECTIONS OF CORROSIVE SUBLIMATE:}

BY JOHN V. SHOEMAKER, A.M., M.D.,

LECTURER ON DERMATOLOGY AT JEFFERSON MEDICAL COLLEGE, LND INSTRUCTOR THEKEON IN THE POST-GRADUATE COURSE OF THAT INSTITUTION; PHYSICIAN TO THE PHILADELPHIA HOSPITAL FOR DISEASES OF THE SKIN, ETC.

THE hypodermic injection of mercuric chloride for the treatment of syphilis has been received with great caution in the United States of America, notwithstanding that $\mathrm{Dr}_{\mathrm{r}}$ Lewin's book on the subject has been there translated and republished. I was one of the first to take up that treat. ment; and, encouraged by my success with it, read a paper on the subject before the meeting of the American Medical Association at St. Paul, Minnesota, in 1882. I analysed a number of cases treated in this manner by myself at the Philadelphia Hospital for Skin Diseases. I have since then practised it freely, and with even greater success than before, Syphiloderma of all descriptions were made to yield under this treatment, and no disadvantages of any consequence were experienced in its course. I have also tried the various additions and modifications of the original Lewin's mercuric bichloride injections. I have invariably given them up, preferring the method suggested by Lewin, in using a simple watery solution of corrosive sublimate. I have found, how. ever, that the treatment could be carried very much further, and larger doses readily borne, and necessary for a thorough cure, than pointed out by him. I have invariably carried daily increased injections to the point where they produced systemic effect; and $I$ have in many instances made, and found it necessary to make, injections of as much as half a grain (three centigrammes) per day. These strong injections were readily borne, providing they were sufficiently dilute, not less that half a drachm being employed for an injection containing half a grain (three centigrammes) of corrosive sublimate. When three large injections were reached daily, the systemic effect of mercury soon became apparent : as ptyalism, intestinal irritation, and occasional tremor, which, however, soon subsided on the cessation of the injections. Administration of potassium chlorate, and occasionally the exhibition of potassium iodide, althong acting as an adjuvant in the treatment, did not serve to augment the systemic effect of the mercuric bichloride, but rather diminished its characteristic symptom. Stimulation by milk punch, and supporting treatment with ferrous iodide, were of ten found of great utility, but generally after twenty.four to thirty daily injections the syphilitic symptom had disappeared, and where the increasing dose had been persistently continued the relapse proved a rare excep. tion indeed. I attribute the effect of this treatment to a formation of mercuric albuminate in the cellular tissue which, insoluble to the liquids of the organism, gradually dissolved under the peptonising action found every where in the body, and thus produced a peptonised mercuric albuminate readily assimilable and eliminable in and through all parts of the body. I am led to this inference from the fact that otherwise toxic doses were innocent if injected under the skin ; and if it were not for local irritation, I think even larger doses than I have mentioned could be borne without toxic effect. The local effects of the injection seem to bear ont my views. Even large doses produce at most a swelling, which, though producing a somewhat erythematous condition of the skin, never suppurates or gives rise to deeper inflammation. I am free to say that in the thousands of injections I have so made I have never met with an abscess or serious inflammation, though the swelling of mercuric albuminate could be detected for several days. The only precaution I observe is to use a clean gold needle and to inject deep enough into the subcellular or con. nective tissue. Though the pain in these injections is al ways a disadvantage, if the solution is sufficiently diluted it will be lessened to a considerable degree, or augmented if more concentrated. No addition of any kind has in $m$ hands lessened this, although $I$ have with advantage ad-

I Resd before the Section of Dermatology at the International Medical Congress at Copenhagen, August 12th, 1884 . 
ministered a quarter of a grain (a centigramme and a half) of morphine sulphate into the arm hypodermically prior to the injection of the corrosive sublimate. I regard it as necessary, to bring syphilis into abeyance and to obviate an early relapse, to constantly increase the strength of the mercuric chloride until its physiological effects are induced, and to continue its use in less vigorous manner until all symptoms have disappeared, sustaining the patient during this period with aliment, stimulant, and medication. Conducted in this manner, I regard the treatment of syphilis by hypodermic injections of corrosive sublimate as more rapid, reliable, cleanly, and less dangerous than either internal exhibition of mercurials, or iodides, or the combination of the two, or the filthy inunction treatment either with or without variations. In no case have I found it necessary to use more than twenty to thirty injections, though I have frequently continued the after-treatment for a month or two, with decided doses of iodide of potassium.

\section{LOBAR PNEUMONIA.}

BY C. W. SUCKLING, M.D., M.R.C.P. PHYSICIAN TO THE QUEEN'S hOSPITAL, BIRMINGHAM.

DURING the past sixteen months I have had under my care, at the Birmingham Workhouse Infirmary, 100 cases of pneumonia. As this is one of the subjects inquired into by the Collective Investigation Committee, I think it my duty to publish the results of treatment and any facts especially noticeable in these cases.

Of the 100 cases, 73 were men and 27 women; 57 cases recovered and 43 died. The right lower lobe was affected in 40 cases, and the left in 33 ; the right upper lobe was affected in 17, and the left in 7 . More than one lobe was affected in 3. The ages of the patients were as follows :-

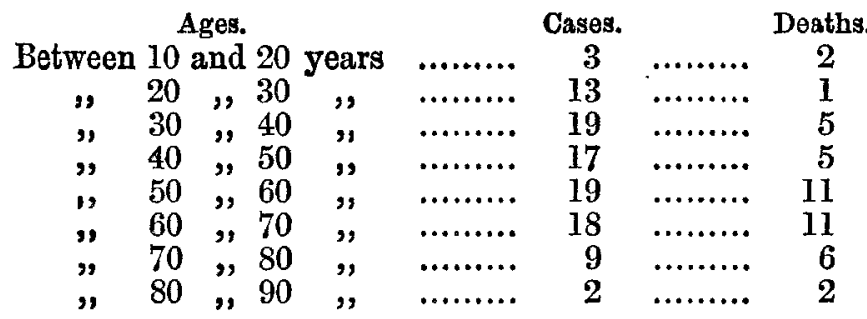

It will be observed that the percentage of deaths increases with the age of the patient. The two deaths which occurred between the ages of ten and twenty years were cases of pneumonia of the upper lobe, one of which was complicated with acute Bright's disease, the pneumonia not being secondary to the kidney mischief, but both being due to the same cause-exposure to cold. In 24 cases the upper lobe was affected, and 10 of these cases were fatal ; in 8 of these 10 fatal cases, there had been previous chronic bronchitis or apical mischief (phthisis). Uncomplicated apical pneumonia is in my experience no more fatal than ordinary pneumonia at the base; but where there has been previous ling mischief it is almost invariably fatal. A pical pneumonia was common in old age ; 7 of the cases occurred in people of over fifty years. In 22 of the 100 cases previous lung mischief in the shape of bronchitis and emphysema existed. I find that where pneumonia supervenes in such cases it is very fatal. It will be observed that the majority (65) of my 100 cases occurred in patients over forty years of age, and there is no doubt that pneumonia in people over this age is greatly to be dreaded. It must also be remembered that the patients are derived from the lowest class of people - a class much addicted to alcoholism, and broken down by want of food and exposure, and therefore exceedingly bad subjects for an acute disease like pneumonia. There is a great contrast between these cases and those I have had as hospital patients; the latter as a rule do well, and we have little dread of pneumonia in 2 young and previously healthy subject.

Rapidity of onset, rusty expectoration, and critical defervescence were the three most constant symptoms in the above cases (in addition to the usual physical signs) Rusty. coloured expectoration occurred in thirty-five cases, and whenever this is present, I take it to be pathognomonic.

As regards temperature, I have only met with hyperpyrexia (a temperature of over $105^{\circ} \mathrm{F}$.) in two cases, and both proved fatal. This may be accounted for by the ages of the patients, for I find that the older the patient the less the degree of pyrexia, and it is in young subjects that we meet with hyperpyrexia in pneumonia. Still, even in old people the temperature chart of pneumonia is characteristic, in that there is always a sudden rise and critical defervescence.

Cyanosis was observed in four cases only; all were over fifty years of age, all had suffered from bronchitis for years, and all proved fatal.

The pulse is the most valuable guide to prognosis in pneumonia. A pulse of over 120 in an adult is serious, and when over 130 the case is generally fatal. In twenty-two cases the pulse was noted to be irregular, and frequently intermittent, often becoming so as death approached. It is my custom to take pulse tracings in all severe cases, and I frequently find inequality in the base line, intermission, and irregularity in volume, often also hyperdicrotism. All such symptoms are to be regarded as very serious, and as a strong indication for the free use of stimulants. In fact, the great majority (I think I may say all) of cases of pneumonia die of heart failure.

Jaundice was observed in four cases, and the right lung was affected in all, the upper lobe in one, the lower in three. Herpes was observed in four cases. Diarrhœa occurred in five fatal cases; it was evidently not critical, for the temperature remained high; diarrhoea, unless critical, is a bad sign. Friction was heard over the inflamed lobe in ten cases. Hyperresonance (occasionally the cracked-pot sound) was frequently observed over the upper lobe when the lower was affected.

As to the cause of the attack, in one case only could I obtain any evidence of infection, and that was in the case of a woman who said, "I caught it from sleeping with my daughter, who has just had inflammation of the lungs." In many cases the disease was clearly attributable to exposure to cold; in several it came on after a bath. The majority of cases among patients previously living in the workhouse occurred during the winter months, when the weather was severe and easterly winds prevailed. It will be observed that nearly three times as many males as females were affected, the mortality being about the same in both.

In a disease like pneumonia, which is shortlived and in which there is such a great tendency to heart failure, a stimulant plan of treatment is in the majority of cases absolutely essential. I know that in children and young adults stimulants may be unnecessary. Aconite and tartar emetic may do good, but in the cases that I have had at the infirmary I dared not give them. In one or two cases where I have used these drugs, the patients being young and the fever high, dicrotism has become marked and delirium has supervened, necessitating the free use of stimulants. So that although it is by no means always necessary to begin with alcoholic stimulants, still I find that it is, as a rule, safest to put the patient on tonics and stimulant medicines-e.g. cinchona and ammonia. I am perfectly sure that I have saved several lives by free stimulation with alcohol; and were I to have pneumonia myself, I would prefer to be under the care of a physician who had no dislike to the use of alcohol in this disease. As to the treatment of hyperpyrexia, quinine is the best remedy, and perhaps the cold pack. I have used the cold bath once; but the effect on the pulse was so bad that I shall never use it again in pneumonia. To ease pain, morphia injections, hot poultices, or a few leeches suffice; I have several times seen good results from the use of the latter. Bloodletting in pneumonia, I believe, is rarely advisable, and in most cases is dangerous. In one case, where there was marked cyanosis, I bled to four or five ounces, with the result that the patient regained consciousness, but afterwards died. Perhaps if it had been done earlier it might have been more effectual. I have lately had four cases (occurring in the workhouse, and therefore seen on the day of the attack), in which the disease has been aborted by quinine in ten-grain doses. All these cases were characterised by rigor, rapid elevation of temperature to $104^{\circ}$ or $105^{\circ} \mathrm{F}$., and by the presence of fine crepitation. After the administration of a single ten-grain dose of quinine the temperature has immediately subsided, and the disease has not progressed, the fine crepitation disappearing in a day or two. For this knowledge $I$ am indebted to Dr. Austin Flint, who says that pneumonia in its early stage may be aborted by quinine. In all cases seen early this mode of treatment ought to be tried. Where the lung will not resolve, I find the frequent application of iodine does good, or an occasional blister.

Birmingham. 